\title{
Application of water treatment sludge for obtaining fertile soil
}

\author{
Leonid Sokolov ${ }^{1, *}$, Svetlana Kolobova ${ }^{1}$, and Viktor Silinskiy ${ }^{1}$ \\ ${ }^{1}$ Vologda State University, Lenina Street 15, Vologda, 160000, Russia
}

\begin{abstract}
The properties of soil obtained from the sludge of water treatment plants were investigated. A new recipe for obtaining soil from peat, river sand and sludge dehydrated with cotton dust was developed. The obtained soil is well structured, resistant to unfavourable mechanical and physical-chemical impacts. It is recommended for creating lawns, planting sports grounds, squares and road slopes. It can be used for filling landfills of solid municipal waste, for strengthening river banks and reservoirs, for soil protection, as well as for production of fertile soils in horticultural and urban farms, when growing vegetables, berries and flowers in greenhouses. The studied soil expands the range of plant nutrient mixtures, is based on the use of available raw materials, and is not difficult to prepare.
\end{abstract}

\section{Introduction}

The problem of technogenic pollution and soil degradation is extremely relevant for urban areas. In cities, under the influence of intense anthropogenic load, the soils disappear, be-come polluted and degrade, and the possibilities of natural formation and maintenance of soil cover are destroyed [1,2]. Specific requirements are imposed on urban soils: they must be resistant to unfavourable factors, possess increased buffering (the property of soil to prevent a change in its $\mathrm{pH}$ reaction under the influence of acids and alkalis). When the fertile layer is irreversibly polluted, it must be completely replaced with natural or artificial soils $[3,4]$. The experience of reclamation of urban soils has shown that peat-mineral mix-tures without the addition of other organic components are characterized by rapid drying out, potential flammability on city lawns, dusting and a low content of readily available mineral salts, since peat contains mainly difficult-to-oxidize organic matter $[5,6]$.

One of the ways to solve the problem of polluted and degraded urban soils is to use in green building of soils formed on the basis of sludge of water treatment facilities [7-13]. The water sludge has agrochemical properties that make it a sapropel: a sufficient content of organic matter, nitrogen, phosphorus, potassium, a favourable $\mathrm{pH}$ range. However, it is characterized by unfavourable agrophysical properties (lack of soil structure, unfavourable water-air regime for seeds and roots, the ability to crack when drying). Therefore, in green farming it can be used only in a mixture with other soils $[14,15]$. The water treatment sludge, being a source of nutrition available to plants, contains a significant amount of aluminium salts and hydroxide with amphoteric properties, which allows the soil to exhibit high buffering in relation to highly acidic or highly alkaline surface waters of the urban environment. The introduction of sludge into soils is harmless as it doesn't contain heavy metal salts and organic toxicants.

In terms of the content of toxic elements, pesticides, radionuclides, 3,4 benzo(a)pyrene, oil products, the water sludge meets the sanitary and epidemiological requirements and the requirements for soil quality.

The aim of this paper is to study the possibility of using tap sludge in the composition of fertile soils through the use of available raw materials, including cotton processing waste in the form of cotton dust. This will contribute to the solution of issues of low-waste production and improvement of the ecological situation. The expected technical result of the study was the creation of a new soil composition based on peat, sand, water sludge and cotton dust for growing plants and creating lawns, planting sports grounds, squares and road slopes, expanding the range of plant nutrient mixtures and having high anti-erosion properties [16].

To solve this aim, the following tasks were formulated and implemented: to determine the components ratio in the obtained soil; to establish the impact of sludge in the composition of soils on germination and morphometric parameters of seedlings of the test culture.

The main components of the studied soil are sand, fine particles of which form the ba-sis, the skeleton of the soil - soil mixture, peat, which is a source of humus organic matter formed during the decomposition of plant and animal residues, water sludge - an analogue of natural sapropel containing up to $40 \%$ of fertile humus, and cotton dust, which has moisture absorption properties and plays the role of a regulator of the moisture regime of the soil. Neither sand nor peat can create a solid soil structure. This function is performed by the sludge, by sticking particles of sand and peat.

The studied soil absorbs and retains moisture well, its structure retains two types of porosity - capillary and non-capillary. Moisture from rain, melting snow and

\footnotetext{
* Corresponding author: sokolovli@mail.ru
} 
groundwater is absorbed through the capillary gaps between soil particles, and air takes up non-capillary voids. Such a soil, possessing a place for both water and air, is able to maintain its structure for a long time [17].

\section{Materials and methods}

Initially, the properties of the soil components were studied. For microscopic studies, the CELESTRON microscope was used.

At the second stage, we studied the impact of the sludge taken from the water treatment facilities in Vologda, in combination with cotton dust. The growing experiment was carried out by the method of seedlings according to the Russian State Standard GOST 1203884. The test samplings were of various compositions:

- Sample 1. Peat + Sand (1:1);

- Sample 2. Peat + Sand + Sludge (5:5:1);

- Sample 3. Peat + Sand + Sludge + cotton dust $(5: 4: 2: 0.1)$

- Sample 4. Peat + Sand + Sludge + cotton dust (4:3:3:0.2);

- Sample 5. Peat + Sand + Sludge + cotton dust (3:4:3:0.1).

Seeds for creating a decorative lawn ("universal lawn") with the following composition of grasses were used as a test culture: Festulolium $-10 \%$, Meadow fescue - 10\%, Annual ryegrass - 30\%, Timothy grass - 10\%, Reed fescue - $10 \%$, Perennial ryegrass - 30\%. Baths with the appropriate soil for germination were placed in the KS-200 SPU climatostat. The experiment was repeated 5 times. The seeds were germinated at a temperature of $20^{\circ} \mathrm{C}$ with a preset program for changing the "day" and "night".

Germination was determined on the 7th and 20th day. On the 7th day, 3 baths with soil of each variant were removed. The root system of seedlings was washed, the number of roots was counted, and biometric measurements were carried out: the length and weight of the root system, the length and weight of the seedlings. On the 15th day after sowing the seeds, biometric measurements were repeated with the remaining baths, the mass of the root system and the mass of seedlings were estimated with photographic recording.

During experiments the content of trace elements and its components in the soil was determined using the atomic absorption flame spectrometer "ConterAA 300" with flame atomization and the atomic absorption spectrometer "MGA 915" with electrothermal atomization.

For statistical processing of the obtained results, the analysis of variance of the experimental data was performed using the Microsoft Excel 2010.

\section{Results and discussion}

Water treatment sludge is a multicomponent gel-like spatial structure with a highly developed surface. The main components of the sludge are the products of hydrolysis of chemical reagents in combination with minerals (clay particles, fine sand, carbonate rocks, insoluble or slightly soluble metal salts) and organic substances (silt, phyto- and zooplankton, various microorganisms and bacteria, waste products of aquatic organisms and plants, colloids of humic acids and fulvic acids). The dispersion composition of the sludge is represented by coarse mineral and organic particles ranging in size from 10-4 $\mathrm{mm}$ and more. The content of dry matter in the sludge was $0.3-0.4 \%$, the content of mineral impurities in the form of sand, clays (insoluble residue) was $2-15 \%$, losses on ignition reached $70 \%$ or more.

The content of organic carbon in the dry sludge ranged from 12 to $20 \%$, which increased the carbon nutrition of plants. The maximum values corresponded to periods of increased content of humic substances in the sludge, which constitute the bulk of organic impurities. The amount of silicon oxide $\mathrm{SiO} 2$ in the precipitate was $5 \%-8.5 \%$ of the dry matter mass. A micrograph of the investigated sludge is shown in Figure 1.

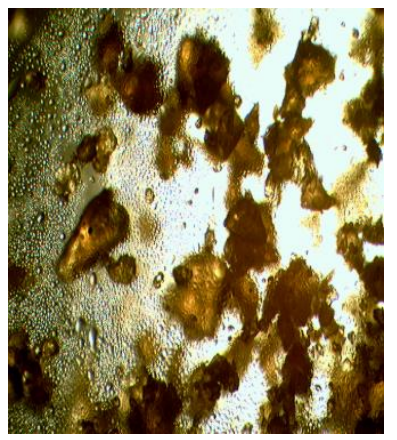

Fig. 1. Sludge of water treatment facilities ( $\mathrm{x} 4$ magnification).

The investigated sludge contained: $14.12 \%$ of sand, $2.3 \%$ of aluminum, $10.40 \%$ of organic matter, $1 \%$ of iron, $1.38 \%$ of nitrogen and $0.02 \%$ of phosphorus. The potassium content was about $0.1 \%$ (by K2O). The sludge obtained from washing of the fast filters and blowing of the settling tanks had a moisture content of $98 \%$.

To obtain soil, quarry, coarse-grained river sand was used (Figure 2).

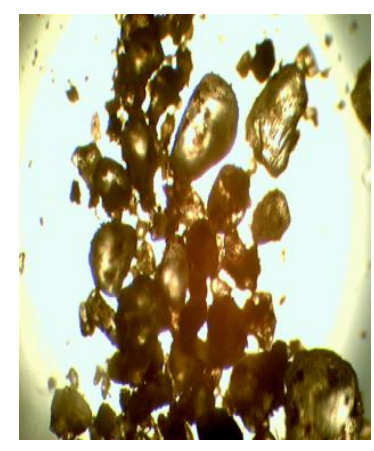

Fig. 2. River sand (x4 magnification).

Peat contains a large amount of organic matter, a significant part of which belongs to the compounds of humic acids, a significant amount of nitrogen, has high moisture and gas filling properties. It is characterized by the absence of disease-causing principles and antiseptic properties. For the preparation of the soil, peat of $40 \%$ - 
Table 1. The influence of the water treatment facilities sludge on lawn seedlings.

\begin{tabular}{|c|c|c|c|c|c|}
\hline \multirow{2}{*}{ Options } & \multicolumn{2}{|c|}{ Germinating capacity, \% } & $\begin{array}{c}\text { Amount of roots, } \\
\text { pcs }\end{array}$ & $\begin{array}{c}\text { Root system } \\
\text { length, mm }\end{array}$ & $\begin{array}{c}\text { Seedling length, } \\
\text { mm }\end{array}$ \\
\cline { 2 - 3 } & On the 7th day & On the 20th day & 5 & 60 & 120 \\
\hline Sample No. 1 & 26 & 92 & 7 & 31 & 110 \\
\hline Sample No. 2 & 40 & 85 & 6 & 65 & 110 \\
\hline Sample No. 3 & 35 & 74.5 & 8 & 61 & 120 \\
\hline Sample No. 4 & 47 & 96 & 3 & 15 & 100 \\
\hline Sample No. 5 & 15 & 60 & 3 & \\
\hline
\end{tabular}

$60 \%$ moisture was used. It was low-lying meadow peat formed in lowlands under the conditions of excessive moisture and lack of oxygen.

A large reserve of organic raw materials for the preparation of soil and regulation of its moisture regime in the experiment was cotton dust - waste from cotton processing, weaving and textile enterprises. A micrograph of cotton dust is shown in Figure 3.

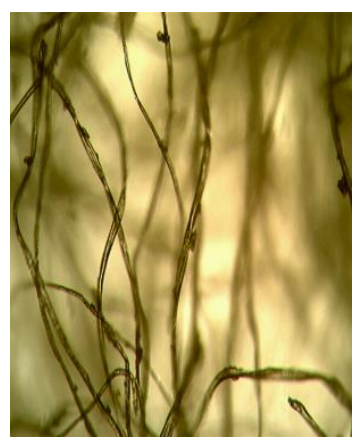

Fig. 3. Cotton dust ( $x 4$ magnification).

Cotton dust contains all the main nutrients that become available to plants during mineralization. It is rich in organic compounds readily available for microflora - cellulose, lignin, pectin. Cotton dust possesses moisture absorption properties, due to the capillary structure of its fibers, it is able to accumulate and release moisture depending on external moisture, and thereby serves as a regulator of the moisture regime of the soil. The investigated cotton dust had an ash content of 9.0-9.3 and the $\mathrm{pH}$ of 6.7-6.9. The dust contained $93.8 \%$ of cellulose, $3.4 \%$ of pectin, $0.6 \%$ of lignin, $0.7 \%$ of waxy substances, $1.3 \%$ of water, the rest was minerals. The dust contained fibers 5-20 mm long and 20-22 $\mu \mathrm{m}$ thick. The thermal conductivity of cotton dust was $0.04 \mathrm{~W} / \mathrm{m}^{\circ}{ }^{\circ} \mathrm{C}$. As a result of the experiment, it was found that the addition of cotton dust to the sludge (at a ratio of 1:10) reduces the $\mathrm{pH}$ of the sludge from 6.7 to 6.4 , while the ash content of the sludge also decreased to $9.32 \%$ with the initial $32 \%$. Fig. 4 shows the relationship between the decrease in the moisture content of the sludge (at a volume of $100 \mathrm{ml}$ ) as a result of mixing with cotton dust.

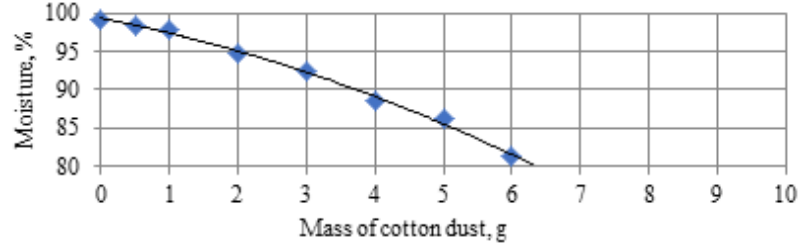

Fig. 4. Decrease in water sludge moisture as a function on the amount of added cotton dust.

The results of the growing experience are presented in table 1.

The sludge mixed with peat and sand on the 7 th day increased the mass of seedlings by $27 \%$ and by $34 \%$ when cotton dust was added to it. This tendency continued on the 15 th day after sowing the seeds. The formation of soil aggregates of different sizes upon addition of sludge to sand and peat indicates an active process of structure formation [18]. Thus, the obtained results confirmed the possibility of using the sludge of water treatment plants as a structure-forming component of the soil.

Practical use of water treatment sludge, its mixing with other soil components can be carried out on the territory of water treatment facilities using screw-type mixers. Large volumes of soil are prepared as follows. The calculated in accordance with the recipe amounts of peat, sand, water sludge and cotton dust are unloaded from vehicles next to each other onto a concrete platform. Initially, the water sludge is mixed with cotton dust. During mixing, the calculated dose of cotton dust is evenly introduced into the mixed mass of sludge. Stirring is carried out until a homogeneous mass is obtained. Mixing of the entire mixture of raw materials (peat, sand, sludge, cotton) is carried out by a front-end loader with a hinged bucket by repeatedly (at least 20 times) gripping and overturning the mixture. Mixing is carried out until the starting materials are completely mixed, the completeness of mixing is determined visually. Mixing and crushing of soil obtained after the initial mixing of raw materials is carried out by passing it through the ALLU DS 3-23 bucket crusher installed on a front loader. The finished mixture (soil) is transferred to the storage area or loaded with a front loader into dump trucks for shipment to the consumer. The resulting soil does not dry out and does not ignite, contains $15-20 \%$ of organic matter, nitrogen, phosphorus and potassium in forms accessible to plants (in a mass ratio of $7: 4: 1$ ), its $\mathrm{pH}$ is $6.5-7.5$.

The water treatment facilities sludge has a low content of metals, so it can be used as a component that 


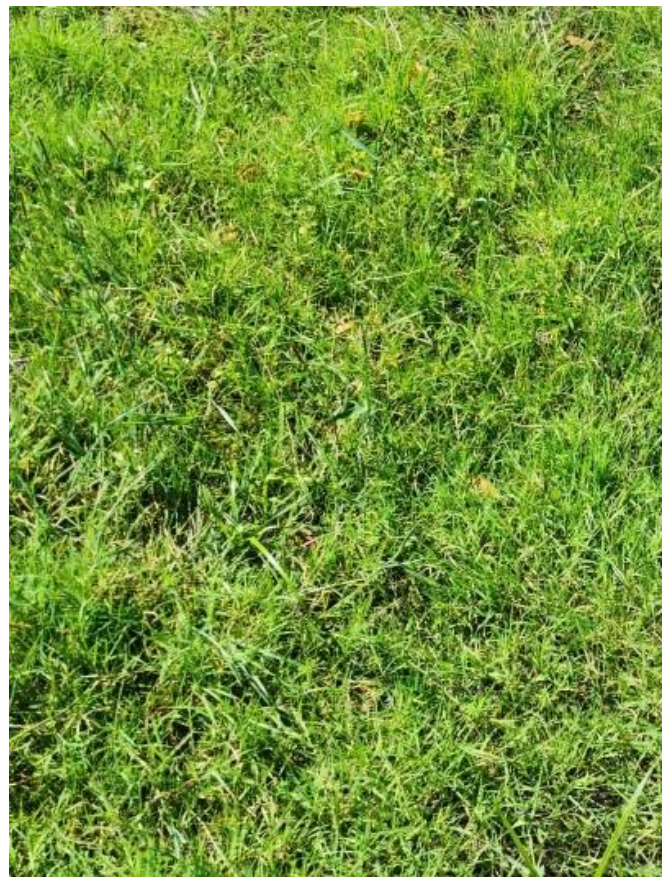

a)

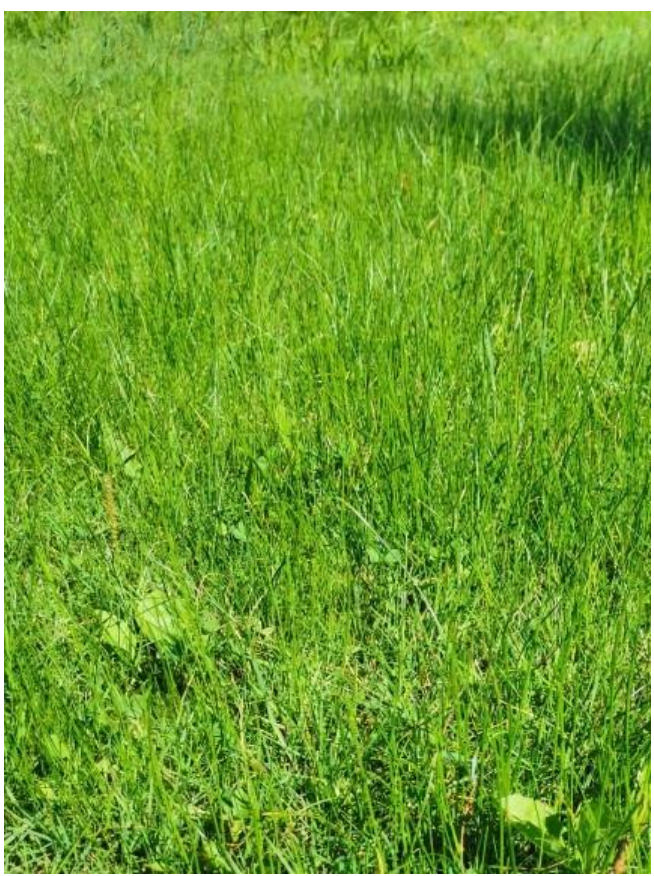

b)

Fig. 5. Photograph of the lawn formed on soil obtained from water treatment plant sludge : a) on the 20th day after lawning; b) in a month after lawning.

reduces the concentration of toxicants in soils. Moreover, the metals present in it are micronutrients for plants. As a result, the soil becomes a conditional balanced fertilizer.

The sludge of water treatment plants contains a significant amount of aluminum salts and hydroxides with amphoteric properties. Therefore, the soil can exhibit increased resistance to changes in the acid-base balance in urban conditions, when pollutants (acid rain, cement dust, ash from thermal power plants) are continuously supplied to the soil and can change acidbase conditions.

The lawn formed from the studied soil showed extremely high resistance to drying out in extremely dry summer conditions. The planted grasses did not die without irrigation on any of the lawns and quickly recovered after the first rains (Figure 4).

\section{Conclusions}

Developed was a new recipe for obtaining soil using sludge from water treatment plants. Studies have shown that when sand and peat are supplemented by the sludge of water treatment plants and dust-dehydrated cotton, the structure formation processes actively occur. The performed complex physical studies show that the obtained soil is well structured, resistant to unfavourable mechanical and physical-chemical impacts. This soil is recommended to be used to make lawns, for filling landfills of municipal waste, in road construction for filling slopes of embankments for soil stabilization and growing perennial grasses. In can be used to strengthen river banks and reservoirs; for soil protection; for production of fertile soil in horticultural and urban farms; for growing vegetables, berries and flowers in greenhouses; for landscaping squares and sports grounds. The obtained soil expands the range of plant nutrient mixtures, is based on the use of available raw materials, and is not difficult to prepare.

\section{References}

1. S. K. Maiti and J. Ahirwal, in Phytomanagement Polluted Sites Mark. Oppor. Sustain. Phytoremediation (2019), pp. 83-111

2. J. Sandor, C. L. Burras, and M. Thompson, in Encycl. Soils Environ. (Elsevier, Oxford, 2005), pp. 520-532

3. Soil Science Fundamentals Exam. Performance Objectives (2018)

4. S. D. Kalev and G. S. Toor, in Green Chem. An Incl. Approach (2018), pp. 339-357

5. M. K. Doula and A. Sarris, in Environ. Dev. Basic Princ. Hum. Act. Environ. Implic. (Elsevier, Amsterdam, 2016), pp. 213-286

6. K. R. Olson, in Encycl. Soils Environ. (Elsevier, Oxford, 2004), pp. 532-535

7. N. Politaeva, Y. Smyatskaya, and A. Fedyukhin, Desalin. Water Treat. 174, 116 (2020)

8. J. De Oña and F. Osorio, J. Hazard. Mater. 131, 37 (2006)

9. E. Epstein, J. Environ. Qual. 4, 139 (1975)

10. M. M. Al-Sharif and M. F. Attom, in Environ. Pipeline Eng. 2000 (2000), pp. 378-388 
11. D. A. Cauich-López, L. F. Barrera Payan, A. M. N. Abdelhalim, E. Socolova, A. A. Sinitsyn, and I. G. Akhmetova, Int. J. Civ. Eng. Technol. 10, 2118 (2019)

12. I. A. Sultanguzin, E. V Zhigulina, Y. V Yavorovsky, I. D. Kalyakin, A. V Govorin, A. V Fedyukhin, A. A. Krolin, S. V Guzhov, O. Derevianko, and L. Mukhametova, in (2019)

13. N. Politaeva, V. Prokhorov, E. I. Lezhnev, V. A. Polyanskii, B. G. Matisov, L. R. Mukhametova, and I. A. Mukhin, IOP Conf. Ser. Earth Environ. Sci. 337, (2019)

14. C. Bristow and N. P. Mountney, in Treatise Geomorphol. (2013), pp. 246-268

15. A. Surikova, E. Sytsyanko, E. Solov'Eva, and L. Mukhametova, E3S Web Conf. 178, (2020)

16. P. Chakravarty and M. Kumar, in Phytomanagement Polluted Sites Mark. Oppor. Sustain. Phytoremediation (2018), pp. 203-219

17. W. J. Likos and R. Jaafar, J. Geotech. Geoenvironmental Eng. 140, 04014043 (2014)

18. A. F. Cabalar and W. S. Mustafa, Eng. Geol. 192, 154 (2015). 